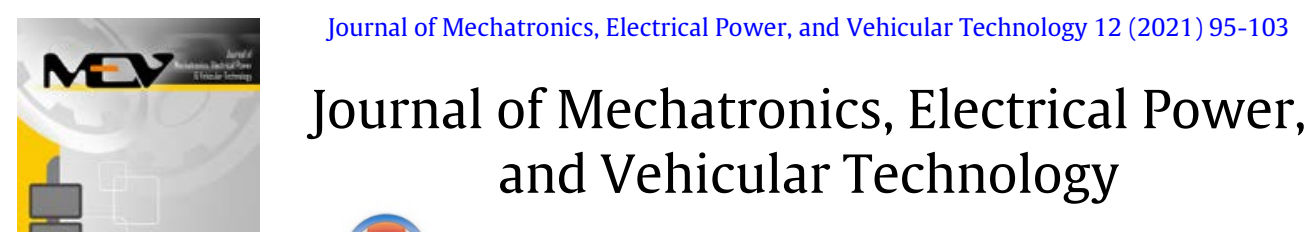

e-ISSN: 2088-6985

p-ISSN: 2087-3379

mev.lipi.go.id

\title{
Effect of different core materials in very low voltage induction motors for electric vehicle
}

\author{
Fransisco Danang Wijaya ${ }^{\mathrm{a}, *}$, Iftitah Imawati ${ }^{\mathrm{b}}$, Muhammad Yasirroni ${ }^{\mathrm{a}}$, \\ Adha Imam Cahyadi ${ }^{\text {a }}$ \\ ${ }^{a}$ Department of Electrical Engineering and Information Technology, Universitas Gadjah Mada \\ Jl. Grafika 2, Yogyakarta, 55283, Indonesia \\ ${ }^{b}$ Department of Electrical Engineering, Universitas Islam Indonesia \\ Jl. Kaliurang km 11, Yogyakarta, 55281, Indonesia
}

Received 5 September 2021; Accepted 16 November 2021; Published online 31 December 2021

\begin{abstract}
The use of squirrel cage induction motor for electric vehicle (EV) has been increasingly popular than permanent magnet and brushless motors due to their independence on rare materials. However, its performance is significantly affected by the core materials. In this research, induction motors performance with various core materials (M19_24G, Arnon7, and nickel steel carpenter) are studied in very low voltage. Three phases, $50 \mathrm{~Hz}, 5 \mathrm{HP}, 48 \mathrm{~V}$ induction motor were used as the propulsion force testbed applied for a golf cart EV. The aims are to identify loss distribution according to core materials and compare power density and cost. The design process firstly determines the motor specifications, then calculates the dimensions, windings, stator, and rotor slots using MATLAB. The parameters obtained are used as inputs to ANSYS Maxwell to calculate induction motor performance. Finally, the design simulations are carried out on RMxprt and 2D transient software to determine the loss characteristics of core materials. It is found that the stator winding dominates the loss distribution. Winding losses have accounted for $52-55 \%$ of the total loss, followed by rotor winding losses around $25-27 \%$ and losses in the core around $1-7 \%$. Based on the three materials tested, nickel steel carpenter and M19_24G attain the highest efficiency with $83.27 \%$ and $83.10 \%$, respectively, while M19_24G and Arnon7 possess the highest power density with $0.37 \mathrm{~kW} / \mathrm{kg}$ and $0.38 \mathrm{~kW} / \mathrm{kg}$ whereas, in term of production cost, the Arnon7 is the lowest.
\end{abstract}

(C2021 Research Center for Electrical Power and Mechatronics - Indonesian Institute of Sciences. This is an open access article under the CC BY-NC-SA license (https://creativecommons.org/licenses/by-nc-sa/4.0/).

Keywords: squirrel cage induction motor; power losses; power density; power efficiency; loss distribution.

\section{Introduction}

Recently, efforts to reduce gas emissions to make global improvements have been made in many sectors, for example, by switching to electric vehicles transportation. It is shown that the electric vehicles can significantly reduce dependence on fossil fuels. One of the main components of electric vehicles is its electric motors [1][2]. In general, electric motors use permanent magnets such as the permanent magnet synchronous motor (PMSM) and brushless DC motor (BLDC). However, the increasing use of permanent magnets as electric vehicle becomes more problematic as it uses an extremely rare material. In order to reduce the dependency on permanent magnet material, the utilization of

* Corresponding Author. Tel: +62-74-552330
E-mail address: danangwijaya@ugm.ac.id induction motors can play a key role [3][4][5].

Squirrel cage induction motor (SCIM) is one type of motor that can be used in electric vehicles [6]. This SCIM has been used in various applications such as in golf cart electric vehicles which has been intensively used in resorts, hotels and retirement villages, airports, shopping malls, hospital, university campus, and others. As an induction motor is always supplied by an AC voltage, hence it must be equipped with an inverter to change the DC voltage from the battery to $A C$ voltage. In addition, the AC voltage needs to be controlled to regulate the speed of the induction motor. Extra or very low voltage system of induction motor for EVs has been discussed in [7][8][9] to avoid the high voltage human risks, expensive and complex insulation of high voltage system, and reduce $\mathrm{dV} / \mathrm{dt}$ (the instantaneous rate of voltage changes with respect to time) which may affect the system reliability and 
motor life-time. Therefore, very low voltage as defined in IEC 61140:2016 is selected to suplly induction motor as EV drivers in this research.

Although an SCIM has simple construction, it has advantages of strong, fast, high-speed areas with inverters, low ripple, and minimum maintenance. Unfortunately, this motor also has a low efficiency [10]. To improve the efficiency, it can be done by reducing the components that contribute to power losses. There are five components of induction motor loss, namely stator loss, rotor loss, core loss, stray loss and mechanical loss. Design and calculation on SCIM for mini electric vehicle has been done in [11] with $43 \mathrm{~V}, 50 \mathrm{~Hz}, 4 \mathrm{~kW}$ using cast aluminium and copper for rotor core material. In this research, an SCIM design method with a low power rating of $5 \mathrm{HP}$ and a very low voltage of $48 \mathrm{~V}$ using three materials namely M19_24G, Arnon7, and nickel steel carpenter is developed to identify loss distribution in those loss components. It can be carried out by varying the core material of the stator and rotor. The magnetic materials are the paramount aspect in the design of induction machines especially for those which use only soft magnetic materials (no permanent magnet machines) such as induction motors [12]. In regards to above mentioned problems, this paper investigates the effects of core materials on the performance and losses distribution of induction motors and then compares the power density and cost of each material.

\section{Materials}

The design model is proposed based on the specification rating of SCIM which is identified from standards and material datasheets. Based on this data, a numerical calculation process using MATLAB simulation was done. The result of the calculation will be passed to ANSYS software to get the detail characteristic operation performances [12]. To drive an electric golf cart with rated speed $30 \mathrm{~km} / \mathrm{h}, \mathrm{SCIM}$ design must have fulfilled the technical requirement such as torque to speed characteristics. In the previous research [8][13], NEMA class C motor design was used, whereas this study used a motorcycle design choice that followed NEMA of class A.

\section{A. SCIM design specifications}

In general, motors used in the industry are usually not operated in extreme work cycles. On the other hand, motors for electric vehicle applications must be able to adapt to a driving pattern that can accommodate difference in speed and torque characteristics [14][15]. For example, the constant torque operating area is still needed when the vehicle starts and climbs uphill while the constant power operation area is still needed when the vehicle is traveling at high speed. In constant power region, if the motor is fed by constant voltage, the pull-out torque of the motor decreases proportionally to the squared speed. The typical mechanical characteristic of the induction motor can be seen in Figure 1.
In general, induction motor for electric vehicles is required to control its speed over a wide range in a fixed power operating area. It can be obtained by increasing the breakdown torque value at base speed. As a result, this is one of the considerations in the induction motor design process used for electric vehicles [16]. Other factors that can be considered for electric vehicles are efficiency, power factor and power density $(\mathrm{kW} / \mathrm{kg})$. The design process is initiated by identifying the type or characteristic of the load that will be driven by the motor. The desired specifications are stated in Table 1 and will be used in the calculation.

\section{B. Material specifications}

Various studies have been conducted in the selection of stator and rotor core material for induction motors [17][18][19]. In this study, we focused only on three most common materials used as SCIM cores for fair investigation.

The three materials of M19_24G, Arnon7, and nickel steel carpenter were chosen among the materials that are often used in the SCIM design process. The magnetic properties of each material are represented by the $B-H$ curve as shown in Figure 2 . These three materials also have a constant

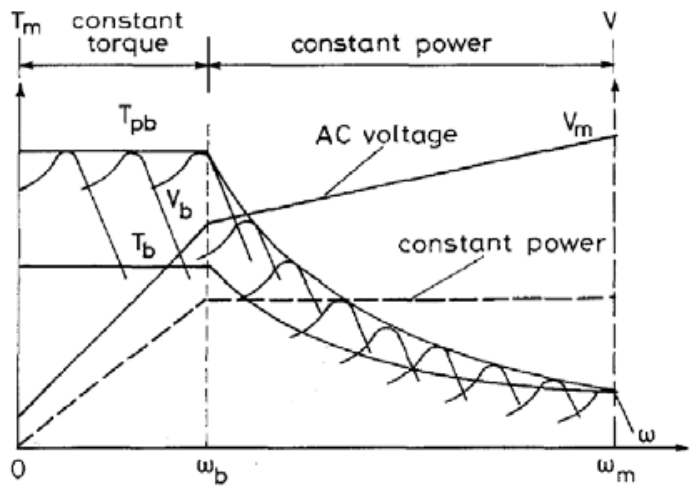

Figure 1. The typical mechanical characteristic of the induction motor for EV

Table 1.

Desired specification of SCIM

\begin{tabular}{clll}
\hline Symbol & Quantity & Value & Unit \\
\hline$P_{n}$ & Output power & 5 & $\mathrm{HP}$ \\
$V_{1 p h}$ & The rated line to the line & 48 & $\mathrm{~V}$ \\
& RMS voltage & & \\
- & Connection type & Wye & - \\
$f_{1}$ & Rated frequency & 50 & $\mathrm{~Hz}$ \\
$2 p 1$ & Number of poles & 4 & - \\
$m$ & Phase number & 3 & - \\
$\omega_{b}$ & Base speed & 1500 & $\mathrm{rpm}$ \\
$\omega_{m}$ & Maximum speed & 4500 & $\mathrm{rpm}$ \\
$T_{n}$ & Rated torque & 24 & $\mathrm{Nm}$ \\
$\eta$ & Efficiency at rated & 0.82 & - \\
$c o s$ & PF at rated & 0.83 & - \\
$S_{n l}$ & Rated slip & $\leq 5 \%$ & - \\
$T_{b k}$ & Breakdown torque & $1.75-3^{\mathrm{a}}$ & $\mathrm{p} . \mathrm{u}$ \\
$T_{L R}$ & Locked rotor torque & $0.7-$ & $\mathrm{p} . \mathrm{u}$ \\
& & $2.75^{\mathrm{a}}$ & \\
$I_{L R}$ & Locked rotor current & $6-8$ & p.u \\
$T$ & Operating temperature & 80 & ${ }^{\circ} \mathrm{C}$ \\
\hline a & &
\end{tabular}

${ }^{a}$ higher value are for motors with lower horsepower ratings 


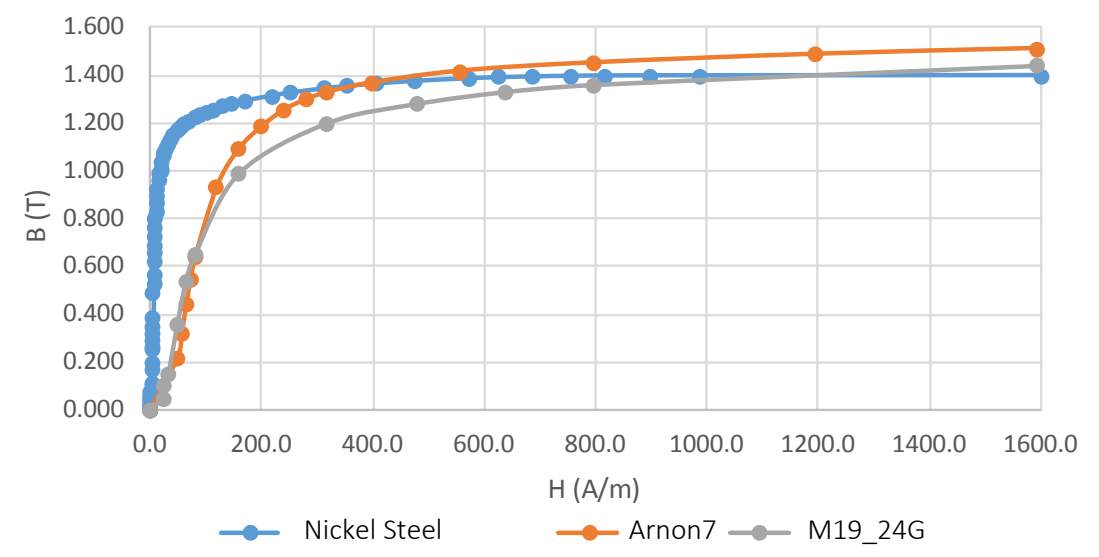

Figure 2. $B$ - $H$ curve of three materials

value to calculate the value of the core losses. The calculation of the software is carried out using the Bertotti expression [18].

According to the loss-separation principle by Bertotti [18], the conventional three-terms iron loss model can be expressed as follows:

$P_{\text {core }}=P_{\text {hyst }}+P_{\text {eddy }}+P_{\text {excess }}$

where,

$$
\begin{aligned}
& P_{\text {hyst }}=K_{h} B^{2} f \\
& P_{\text {eddy }}=K_{c} B^{2} f^{2} \\
& P_{\text {excess }}=K_{e}(B f)^{\frac{3}{2}}
\end{aligned}
$$

The first term represents the loss of hysteresis $\left(P_{\text {hyst }}\right)$, the second term is the loss of the classic Eddy current $\left(P_{\text {eddy }}\right)$, and the latter denotes the loss of excess $\left(P_{\text {excess }}\right)$. The constant values of $\mathrm{K}_{\mathrm{h}}$ (hysteresis constant), $\mathrm{K}_{\mathrm{c}}$ (Eddy current constant) and $\mathrm{K}_{\mathrm{e}}$ (excess constant) for each material can be seen in Table 2 . Value $B$ is the flux density of the core material at a certain frequency (f).

\section{Methods}

There are five kinds of loss present in an induction motor which are stator losses, rotor losses, core losses, stray losses and mechanical losses. Initial stray losses and mechanical losses must be calculated and will be used as inputs for ANSYS Maxwell.

\section{A. Losses}

\section{1) Stray losses}

Despite the fact that stray loss exists, it is normally very difficult to be determined. Based on [17] the stray losses are similar to the assigned

Table 2.

Specification of materials

\begin{tabular}{llll}
\hline Parameter & M19_24G & Arnon7 & Nickel SC \\
\hline$K_{h}$ & 164.20 & 201.60 & 9.44 \\
$K_{c}$ & 1.3 & 0.116 & 0.239 \\
$K_{e}$ & 1.72 & 3.308 & 1.144 \\
Density & $7650 \mathrm{~kg} / \mathrm{m}^{3}$ & $7870 \mathrm{~kg} / \mathrm{m}^{3}$ & $8900 \mathrm{~kg} / \mathrm{m}^{3}$ \\
Price & $4 \$ / \mathrm{kg}$ & $0.9 \$ / \mathrm{kg}$ & $23.17 \$ / \mathrm{kg}$ \\
\hline
\end{tabular}

values of IEC 60034-2-1. The value depends on the power rating $\left(P_{n}\right)$ for $1 \mathrm{~kW}<P_{n}<10 \mathrm{MW}$. Stray losses $\left(P_{s}\right)$ can be expressed in equation (5). Where $P_{1}$ is input power and $P_{2}$ is output power.

$P_{S}=\left[0.025-0.005 \log 10\left(\frac{P_{2}}{1 k W}\right)\right] P_{1}$

\section{2) Mechanical losses}

Mechanical losses are related to complex aerodynamic and friction phenomena, and experimental testing is important. The total mechanical loss $\left(P_{m}\right)$ depends on engine size and pole number. Average mechanical loss of 4 pole motors are around $1.5 \%$ of output power for under $2.2 \mathrm{~kW}$ rating and $1 \%$ above $3.7 \mathrm{~kW}$ rating. The value suggested by [18] is expressed as follows

$P_{m}=0.01 P_{n}$ for $P_{n} \geq 3.7 \mathrm{~kW}$

\section{3) Stator and Rotor winding losses}

These losses occur when current flows in the stator and rotor. When there is a change in the load current flowing in the stator and rotor, they will also change accordingly [19]. The value of stator winding losses $\left(P_{c o}\right)$ and rotor winding losses $\left(P_{A l}\right)$ does not only depend on the stator rated current $\left(I_{1 n}\right)$, but also on the value of the stator and rotor winding resistances $\left(R_{S}\right.$ and $\left.R_{T}\right)$, both losses are expressed as

$P_{C O}=3 R_{S} I_{1 n}^{2}$

$P_{A l}=3 R_{r} I_{1 n}^{2}$

\section{B. Main Dimension}

Calculation of main dimensions starts by determining the transfer power through the air gap $\left(s_{\text {gap }}\right)$ expressed as follows

$S_{\text {gap }}=\frac{K_{E} P_{n}}{\eta \cos \theta}$

After that, $\left(s_{\text {gap }}\right)$ is used to calculate the inside diameter of the stator by choosing a ratio of stator inner diameter and length $(\lambda)$ equals 1.8. As the rule of thumb, greater the ratio, smaller the diameter of the stator [17]. Esson's constant $\left(c_{0}\right)$ is calculated with linear regression approach and can be found by

$C_{0}=4.165 S_{\text {gap }}+119.872$ 
Stator inner diameter $\left(D_{\text {is }}\right)$ can be found by

$D_{i s}=\sqrt[3]{\frac{2 p_{1}}{\pi \lambda} \frac{p_{1}}{f_{1}} \frac{S_{g a p}}{C_{o}}}$

Based on the standard, the ratio of the selected inside and outside diameters of the stator $(\lambda)$ is 0.62 . The length of the stator can be computed as

$L=\frac{\lambda \pi D_{i s}}{2 p_{1}}$

With assumption $2 \mathrm{p}_{1}=4$, the length of the air gap $(g)$ can be obtained as

$g=\left(0.1+0.012 \cdot \sqrt[3]{P_{n}}\right) \cdot 10^{-3} \mathrm{~m}$

The rotor outer diameter value is obtained from the difference between the stator inner diameter and the length of the air gap, while the value of the inner diameter rotor depends on the depth of the rotor slot. Based on these calculations, the difference in materials will not affect the main design of the motor. The design of the main dimensions can be seen in Figure 3 and Table 3 for the same flux density of B.

\section{Stator}

Stator design consists of two parts, namely winding and slot designs. Regulating the stator winding can be carried out by calculating the conductor per slot, the number of strands and wire diameter to be used. The first thing to do when calculating the number of conductors per slot $\left(n_{S}\right)$ is calculating the number of turns per phase $\left(W_{1}\right)$ first with the following formula

$W_{1}=\frac{K_{E} V_{1 p h}}{4 K_{f} K_{W 1} f \Phi}$

$n_{s}=a_{1} W_{1} p_{1}$

where $K_{f}$ is teeth saturation coefficient, $K_{E}$ is emf coefficient, $K_{W 1}$ is stator winding factor; is pole flux, $a_{1}$ is number of current paths in parallel, $q$ is number of slots per pole per phase

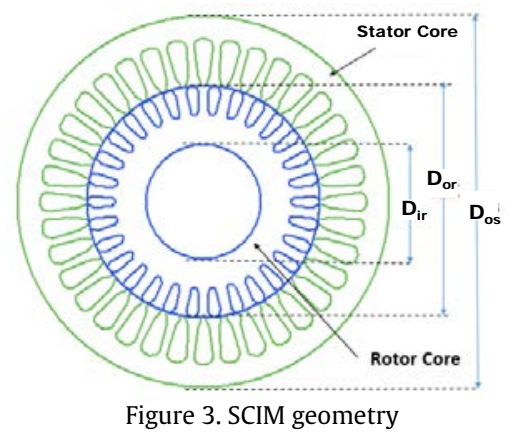

Table 3.

Calculated main dimension

\begin{tabular}{cll}
\hline Symbol & Quantity & Value $(\mathrm{mm})$ \\
\hline$D_{o s}$ & Stator outer diameter & 185.7 \\
$D_{i s}$ & Stator inner diameter & 117 \\
$L$ & Length & 110 \\
$D_{o r}$ & Rotor outer diameter & 116.7 \\
$D_{i r}$ & Rotor inner diameter & 52 \\
$g$ & Air gap & 0.3 \\
\hline
\end{tabular}

The number of the slots $\left(N_{s}\right)$ and area geometry of the slots $\left(A_{s}\right)$ to be used in the design of the stator can be expressed by

$$
\begin{aligned}
& N_{s}=2 p_{1} q m \\
& A_{s}=\frac{\pi d_{\text {Co }} a_{p} n_{s}}{4 K_{\text {Fill }}}
\end{aligned}
$$

where $d_{c o}$ is diameter of the wire, $a_{p}$ is number of conductors in parallel, $K_{\text {Fill }}$ is fill factor.

In this paper, the number of stator slots is 36 slots with each slot containing five conductors with a diameter of $3.081 \mathrm{~mm}$. The stator slot geometry consists of the depth (hs0+hs1+hs2+Rs) and width of the slot (bs2). The selected slot for this motor design is the tapered type. The shape of the slot will influence the reactance of the stator. Based on As calculation, stator slot design that used for this study shown in Figure 4 and Table 4.

Due to the difference in magnetic field strength (H) for the same $B$ magnitude based on the characteristic $B-H$ curve, the bs1 and hs2 value for each design in three materials is different. However this discrepancy is neglected, it is insignificant.

\section{Rotor}

Based on the recommendation given in [19][20], the number rotor slot $\left(N_{r}\right)$ combination corresponding to the number of stator slots used is 30 slots. For the three materials used here, the same design factor does not greatly affect the size of the rotor slots so the geometry design tends to be the same. Rotor slot design used for this study is shown in Figure 5 and Table 5.

The geometry height $\left(h_{s o}, h_{s 1}, h_{s 2}\right)$, back core height $\left(h_{c r}\right)$ and width $\left(b_{s a}, b_{s 1}, b_{s 2}\right)$ components of the rotor slot will affect the diameter of the shaft $\left(D_{\text {shaft }}\right)$ and the length of end ring $(b)$ used in the design is calculated as follows

$$
\begin{aligned}
& \left(D_{\text {shaft }}\right)_{\text {max }} \leq D_{i s}-2 g-2\left(h_{s 1}+h_{s 2}+\frac{\left(b_{s 1}+b_{s 2}\right)}{2}+\right. \\
& \left.h_{c r}\right) \\
& b=(1.1)\left[h_{s 0}+h_{s 1}+b_{s 0}+b_{s 1}+\frac{\left(b_{s 1}+b_{s 2}\right)}{2}\right]
\end{aligned}
$$

The rotor bar current $\left(I_{b}\right)$ and end rings current $\left(I_{e r}\right)$ can be calculated using the following calculation. Where $K_{I}$ is rotor and stator mmf ratio, $N_{T}$ is number of rotor slots.

$$
\begin{aligned}
& I_{b}=K_{I} \frac{2 m W_{1} K_{w 1}}{N_{r}} I_{1 n} \\
& I_{e r}=\frac{I_{b}}{2 \sin \frac{\pi p_{1}}{N_{r}}}
\end{aligned}
$$

The area of rotor bar $\left(A_{e r}\right)$ can be calculated using equation (21), the current density $\left(J_{e r}\right)$ for the selected end ring is $6 \mathrm{~A} / \mathrm{mm}^{2}$ [16].

$A_{e r}=\frac{I_{e r}}{J_{e r}}$

The value of the end ring width $(a)$ is equal to

$a=\frac{A_{e r}}{b}$ 

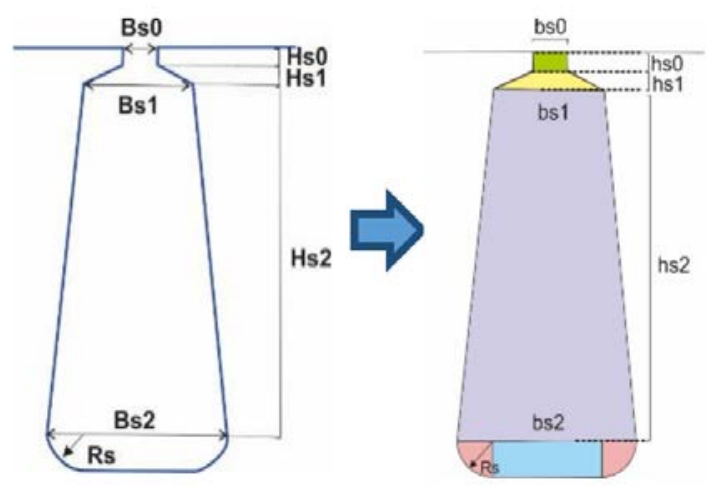

Figure 4. Detailed stator slot [8]

Table 4.

Stator Geometry

\begin{tabular}{ll}
\hline Parameter & Value \\
\hline Ns & 36 slots \\
hs0_stator & $1 \mathrm{~mm}$ \\
hs01_stator & $4 \mathrm{~mm}$ \\
hs2_stator & $15 \mathrm{~mm}$ \\
bs0_stator & $3 \mathrm{~mm}$ \\
bs1_stator & $6.5 \mathrm{~mm}$ \\
bs2_stator & $3 \mathrm{~mm}$ \\
\hline
\end{tabular}

The calculation result from MATLAB for the motor geometry will be used as input into the RMxprt ANSYS Maxwell software.

\section{Results And Discussions}

\section{A. Performance}

Based on RMxprt simulation results, the performance of the motor design under different core materials has no significant differences. The three designs have power factor, rated torque and slip of about $0.93,24.5 \mathrm{Nm}$ and $4-5 \%$. The efficiencies for M19_24G, Arnon7 and nickel steel carpenter core are $83.10 \%, 82.18 \%$ and $83.25 \%$, respectively. The prominent difference was located on the contribution of losses in each motor design. The characteristic of the motors is defined by torque-speed curves as shown in Figure 6. From these curves, locked rotor torque information and breakdown torque data can be found. Furthermore, it is shown that all three materials have different

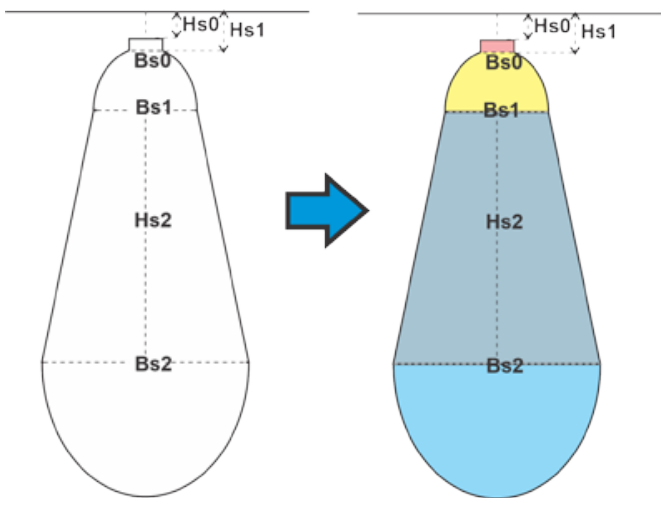

Figure 5. Detailed rotor slot

Table 5.

Rotor geometry

\begin{tabular}{ll}
\hline Parameter & Value \\
\hline $\mathrm{Nr}$ & 30 slots \\
hs0_rotor & $0.5 \mathrm{~mm}$ \\
hs01_rotor & $0.2 \mathrm{~mm}$ \\
hs2_rotor & $10 \mathrm{~mm}$ \\
bs0_rotor & $4 \mathrm{~mm}$ \\
bs1_rotor & $6.3 \mathrm{~mm}$ \\
bs2_rotor & $4 \mathrm{~mm}$ \\
\hline
\end{tabular}

locked rotor torque but when approaching the rating speed, the torque of all three materials has the same magnitude (rated torques of all three designs are the same). The locked rotor torque and the breakdown torque of each design has different values. At low speed, M19_24G material has the greatest value compared to others.

Characteristics of current-speed of the two designs are shown Figure 7 . The curve shows the material with the core M19_24G has the highest initial current or locked rotor current value, followed by Arnon7 and nickel steel carpenter, whose values are 283.297A, 273.951A, and 270.395A. The efficiency-speed curve in Figure 8 shows that the three materials are having similar characteristics. The efficiency at the rated of the design with the nickel steel carpenter material has the highest efficiency, which is $83.24 \%$, followed by Arnon7 and M19_24G with $82.18 \%$ and $82.16 \%$. Figure 9 shows the efficiency-torque of SCIM. At low load torque and high-speed region, the highest efficiency occurs.

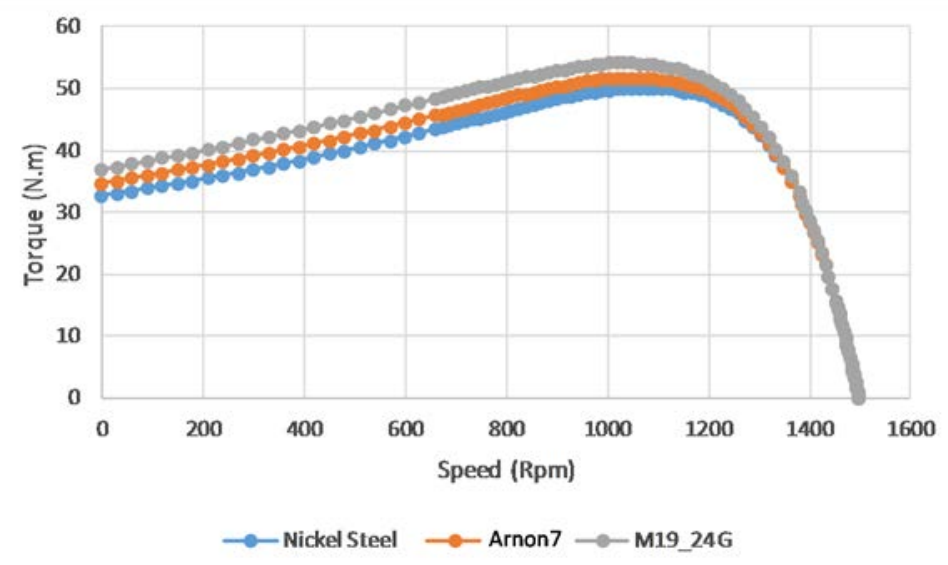

Figure 6. Torque-speed curve of three materials 


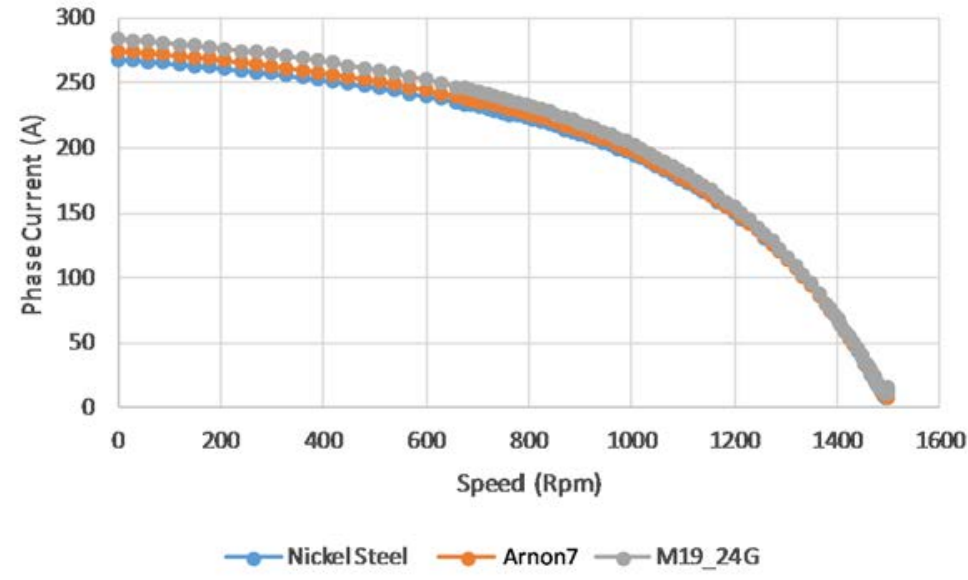

Figure 7. Current-speed curve of three materials

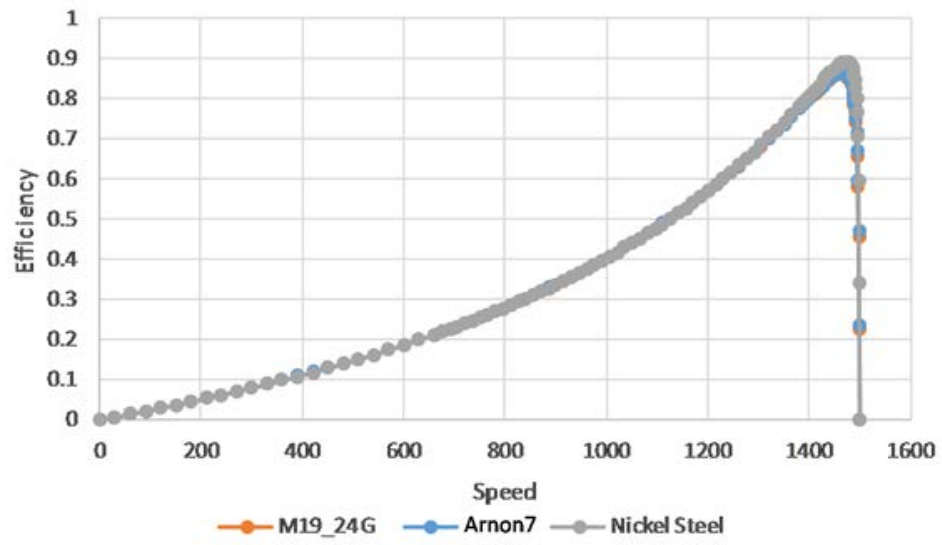

Figure 8. Efficiency-speed curve of three materials

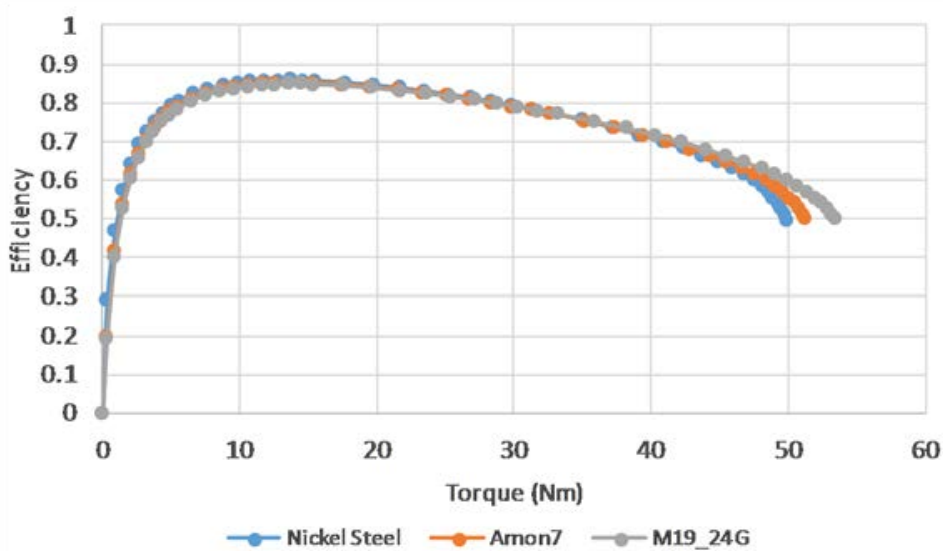

Figure 9. Efficiency-torque curve of three materials

Moreover, since the torque increases with speed reduction, there is no significant difference in efficiency between three materials at high speed.

After creating the basic structure of the IM, the geometry and the materials can be converted to the Maxwell Magnetic Analysis Software. The software is configured by 2D and 3D transient solver options. The program has solutions for $2 \mathrm{D}$ and $3 \mathrm{D}$ transient solvers. For this part of the study, we used 2D to analyze the design. The result of the $2 \mathrm{D}$ transient is shown in Figure 10 and Figure 11 shows the starting torque and the current for the time response. It is also seen how the specified torque-speed values are precisely met. The results of the analytical design and the 2D transient finite element analysis (FEA) are confirmed by the constant current, speed, torque and power factor.

\section{B. Losses Distribution}

Based on the results of the simulation of RMxprt using these three different materials, it found that the distribution of losses in the induction motor is dominated by losses in the winding stator as shown in Figure 12. Winding stator losses have accounted for around 52-55 \% of the total loss, followed by losses on the winding rotor around 25-27\% and 


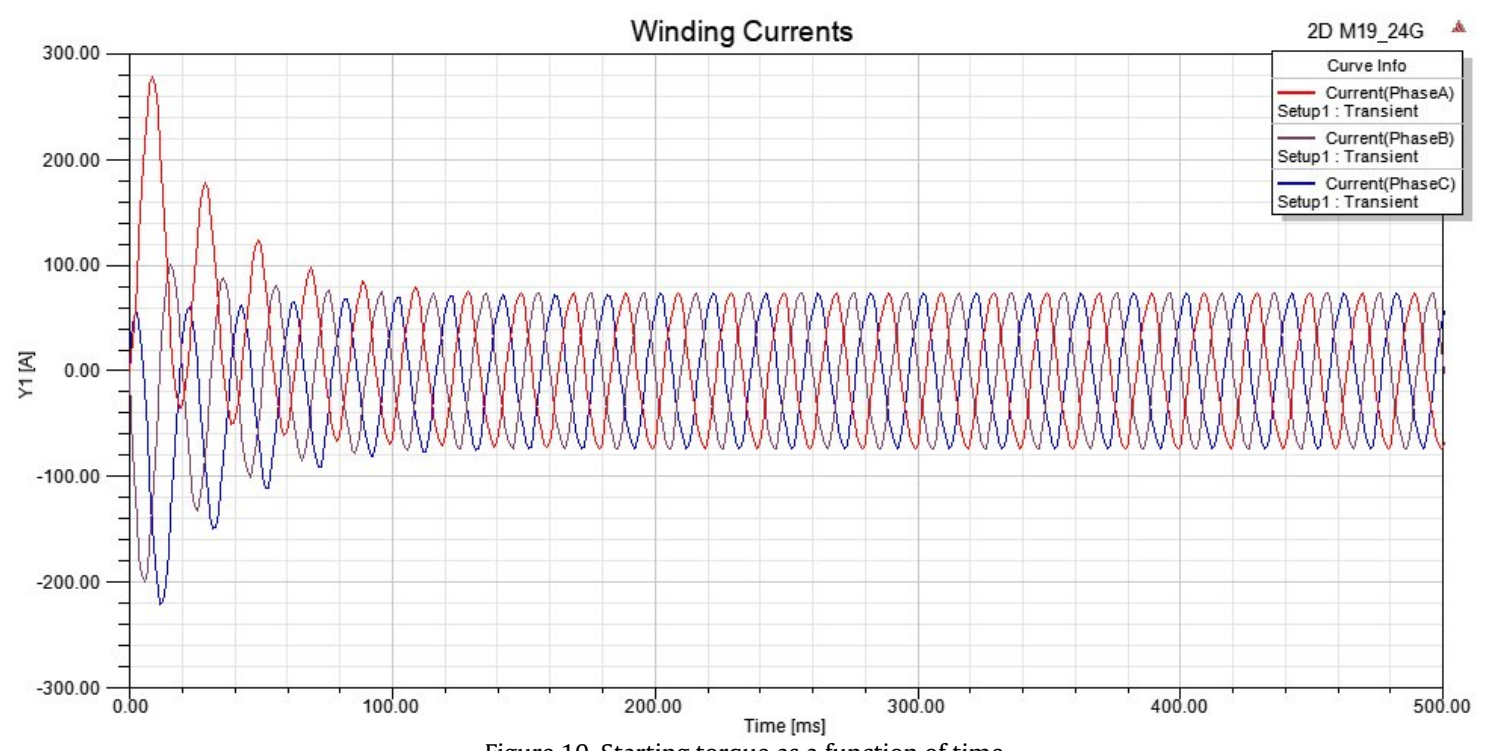

Figure 10. Starting torque as a function of time

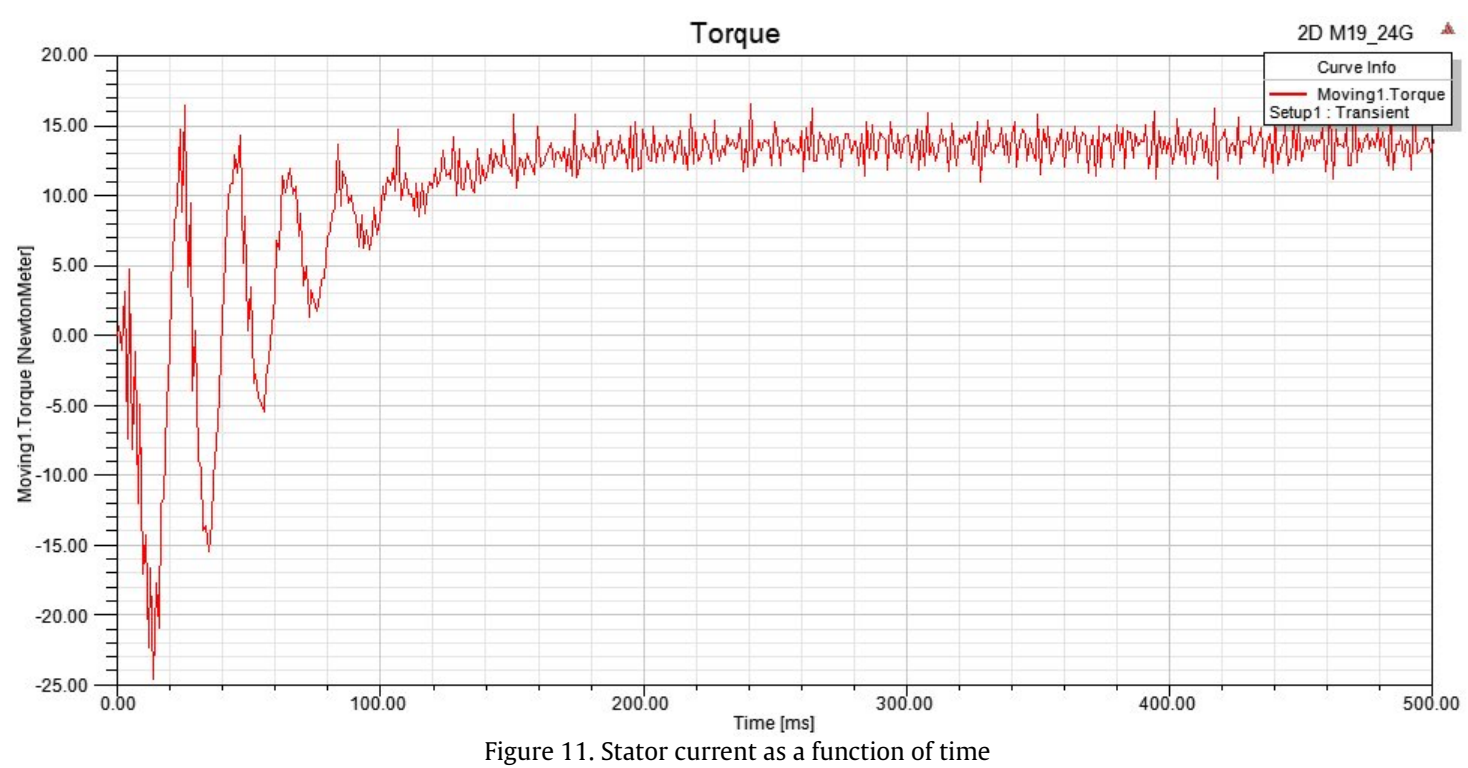

Table 6.

Material consumption and power density

\begin{tabular}{|c|c|c|c|c|c|}
\hline \multirow{2}{*}{ Materials } & \multirow{2}{*}{$\begin{array}{l}\text { Net weight } \\
(\mathrm{kg})\end{array}$} & \multicolumn{2}{|c|}{ Core consumption } & \multirow{2}{*}{$\begin{array}{l}\text { Power density } \\
(\mathrm{kW} / \mathrm{kg})\end{array}$} & \multirow{2}{*}{$\begin{array}{l}\text { Cost core production } \\
(\$)\end{array}$} \\
\hline & & Stator $(\mathrm{kg})$ & Rotor (kg) & & \\
\hline M19_24G & 9.719 & 15.101 & 12.057 & 0.380 & 108.632 \\
\hline Arnon7 & 9.987 & 15.500 & 12.404 & 0.370 & 25.144 \\
\hline Nickel_SC & 20.795 & 17.576 & 14.072 & 0.180 & 733.284 \\
\hline
\end{tabular}

losses caused by the core around 1-7 \%. In the calculation, the value of stray losses and mechanical losses are determined, each of which is $5 \%$ and $11 \%$ of total loss. The total loss of SCIM with materials; M19_24G, Arnon7 and nickel steel carpenter were $779.936 \mathrm{~W}, 777.489 \mathrm{~W}$ and $715.765 \mathrm{~W}$. Comparing the result of total loss of SCIM with reference [11] for $34 \mathrm{~V}$, frequency $50 \mathrm{~Hz}$, rated power $4 \mathrm{~kW}$, stator 30 slots, rotor 26 slots, the total loss was 896 watt using cast aluminium core material and 746.2 watt with copper core material. Meanwhile, the SCIM efficiencies were $81.7 \%$ using cast aluminium core material and $86.3 \%$ with copper core material. From the data, it is shown that losses in the core of nickel steel carpenter material have the smallest losses than the other materials. Nickel steel carpenter has the highest efficiency with the smallest core losses.

From RMxprt simulation, we also saw the material consumption needed for the motor core and total net weight in each design, it is shown in Table 6. So we can calculate the cost materials needed for each motor production and the power density for each motor. Depending on the power density of each design, SCIM with M19_24G core has the best power density, however nickel steel carpenter core motor has the worst power density. Moreover, nickel material is rarely used because the price is very expensive compared to the two other materials. Compared to the rotor design in 


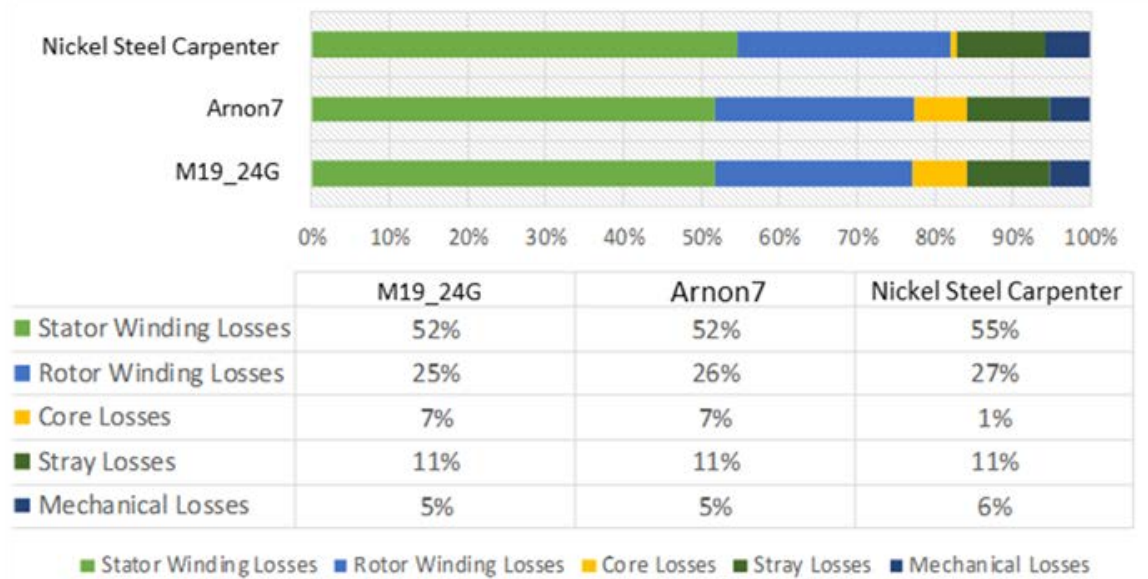

Figure 12. Losses distribution of SCIM

references [8] and [13], the resulting rotor design is easier to fabricate because it only apply single slot rotor.

\section{Conclusion}

The losses distribution of induction motor for very low voltage system applied to golf cart with different core materials (M19_24G, Arnon7, and nickel steel carpenter) had been analyzed. It is seen that the stator winding losses have an approximate of $52-55 \%$ from the total loss, followed by losses on the rotor winding that is around $25-27 \%$ and the losses caused by the core is around 1-7 \% from the total loss. Because of these facts, we conduct further study to minimize the winding of the stator. This can further be used as a reference to enhance SCIM efficiency. Based on the findings in this paper, nickel steel carpenter and M19_24G have the highest efficiency at $83.27 \%$ and $83.10 \%$, respectively. Further, M19_24G and Arnon7 have the highest power density at $0.37 \mathrm{~kW} / \mathrm{kg}$ and $0.38 \mathrm{~kW} / \mathrm{kg}$, respectively. From the discussions we conclude that the cheapest core production is Arnon7 materials.

\section{Acknowledgment}

The authors would like to thank Laboratorium Teknik Tenaga Listrik, Department of Electrical and Information Technology Faculty of Engineering Universitas Gadjah Mada for all the provided facilities.

\section{Declarations}

\section{Author contribution}

Fransisco Danang Wijaya is the main contributor of this paper. All authors read and approved the final paper.

\section{Funding statement}

This research did not receive any specific grant from funding agencies in the public, commercial, or not-forprofit sectors.

\section{Conflict of interest}

The authors declare no conflict of interest.

\section{Additional information}

Reprints and permission information is available at https://mev.lipi.go.id/.

Publisher's Note: Research Centre for Electrical Power and Mechatronics - Indonesian Institute of Sciences remains neutral with regard to jurisdictional claims and institutional affiliations.

\section{References}

[1] K. T. Kim, Hye Eun Song and Gwan Soo Park, "A study on the design of induction motor in low speed urban electric vehicle," IEEE Transportation Electrification Conference and Expo, AsiaPacific (ITEC Asia-Pacific), pp. 866-869, 2016.

[2] M. T. Güneşer, A. Dalcal_, T. Özturk and C. Ocak, "Influence of Rotor slot structure at starting torque and efficiency on urban use EV motor," International Conference on Power Generation Systems and Renewable Energy Technologies (PGSRET), pp. 14, 2019.

[3] A. Marfoli, M. D. Nardo, M. Degano, C. Gerada and W. Jara, "Squirrel cage induction motor: a design-based comparison between aluminium and copper cages," in IEEE Open Journal of Industry Applications, vol. 2, pp. 110-120, 2021.

[4] M. J. Akhtar and R. K. Behera, "An analytical design of an induction motor for electric vehicle application," IEEE 12th International Conference on Compatibility, Power Electronics and Power Engineering, pp. 1-6, 2018.

[5] Y. L. Karnavas, "Influence of soft magnetic materials application to squirrel cage induction motor design and performance," Engineering Journals, vol. 21, pp. 193-206, 2017.

[6] L. Aarniovuori, M. Niemelä, J. Pyrhönen, W. Cao and E. B. Agamloh, "Loss components and performance of modern induction motors," International Conference on Electrical Machines (ICEM) XIII, pp. 1253-1259, 2018.

[7] T. S. Aglan and H. A. Ashour, "Reduced voltage combined ac motor and drive system for safe electric vehicle," First International Conference on Renewable Energies and Vehicular Technology, March, pp. 199-205, 2012.

[8] I. Imawati, F. D. Wijaya and B. Sugiyantoro, "Design and simulation of three phase squirrel cage induction motor in low voltage system $48 \mathrm{~V} 50 \mathrm{~Hz} 3 \mathrm{Hp}$ for electric golf cart," 11th International Conference on Information Technology and Electrical Engineering (ICITEE), pp. 1-6, 2019.

[9] P. Mishra and S Saha, "Design modeling and simulation of low voltage squirrel cage induction motor for medium weight electric vehicle", International Conference on Advances in Computing, August, pp. 1697-1704, 2013.

[10] D. Zhang, J. Shi, H. Zhao and T. Wu, "Loss characteristic analysis of small and medium-sized induction motors fed by PWM inverter based on the experiment measurements," IECON 2017 - 43rd Annual Conference of the IEEE Industrial Electronics Society, pp. 2053-2058, 2017.

[11] Cheng Shukang, Li Cuiping, Chai Feng, Gong Hailong, "Research on induction motor for mini electric vehicles," International Conference on Future Electrical Power and Energy Systems, pp. 249-257, 2012. 
[12] Z. Ferkova, "Comparison of two-phase induction motor modeling in ANSYS Maxwell 2D and 3D program," Elektro, Rajecke Teplice, pp. 279-284, 2014.

[13] I. Imawati, F.D. Wijaya, "Desain dan simulasi motor induksi sangkar tupai tiga fase dengan sistem tegangan rendah $48 \mathrm{~V}$ 50 HZ 3 HP Sebagai Penggerak Kendaraan Listrik Golf Cart," Skripsi, 2019.

[14] H. Toda, K. Senda, S. Morimoto and T. Hiratani, "Influence of various non-oriented electrical steels on motor efficiency and iron loss in switched reluctance motor," IEEE Transactions on Magnetics, vol. 49, no. 7, pp. 3850-3853, 2013.

[15] E. B. Agamloh, A. Boglietti, and A. Cavagnino, "The incremental design efficiency improvement of commercially manufactured induction motors," IEEE Transactions on Industry Applications, vol. 49, no. 6, pp. 2496-2504, Nov. 2013.

[16] Yiming Shen, Changqing Zhu, Xiuhe Wang, "Slot optimization design of induction motor for electric vehicle," The 5th Annual International Conference on Material Science and
Environmental Engineering (MSEE2017), pp 1-7, December 2017.

[17] Rotating electrical machines - part 2-1: standard methods for determining losses and efficiency from tests (excluding machines for traction vehicles). Ed. 2, IEC 60034-2-1, June 2014.

[18] Feng Yanlia, Zhang Chengning, "analytical calculation for predicting the core loss of surface-mounted permanent magnet machine," The sth International Conference on Applied Energy, pp 2119-2124, 2016.

[19] Kim D.J, Chun Y.D, Han Pil-Wan, "The study of the stray load loss and mechanical loss of three phase induction motor considering experimental results," Journal of Electrical Engineering and Technology, vol. 9 Issue 1, pp. 121-126, 2014.

[20] Boldea Ion and Nasar, The induction machines design handbook. 2nd edition, CRC, 2002. 